\title{
Verification of Short Circuit Test Results of Salient Poles Synchronous Generator
}

\author{
Abdul Jabbar Khan ${ }^{1}$, Amjadullah Khattak ${ }^{2}$ \\ ${ }^{1}$ PG Student, University of Engineering and Technology, Peshawar, Department of Electrical Engineering, Pakistan \\ ${ }^{2}$ Associate Professor, University of Engineering and Technology, Peshawar, Department of Electrical Engineering, Pakistan
}

\begin{abstract}
This paper presents that to check the transient response of synchronous generators various tests are performed. Short circuit test is basically for the purpose to find the values of time constants \& reactances of synchronous generator. To check the validity of these time constants \& reactances achieved after the test. A synchronous generator rated 40 MVA with direct connected exciter rated $200 \mathrm{KW}$ installed at Warsak Dam Pakistan is modeled with its various parameters in matlab simulink and its short circuit test is performed. First the theoretical response during short circuit test of each phase of synchronous generator is described, then the matlab simulink response is compared with theoretical response. The results clearly show that the theoretical response completely matches the matlab response. From the results it is deduced that the values of reactances and time constants calculated after a factory short circuit test were correct.
\end{abstract}

Keywords: Synchronous generator (SG), Transient, Short circuit test, Reactance, Time constant.

\section{Introduction}

Power system includes a lot of elements. The major element includes generating system, protection system and a proper distribution system. The most important and expensive system it includes is the generating system. It is the hub where power is produced and then it is transmitted to the consumers. These generators are normally synchronous generators which provide power at a constant speed. Its various parts are shown in fig 1. [3]

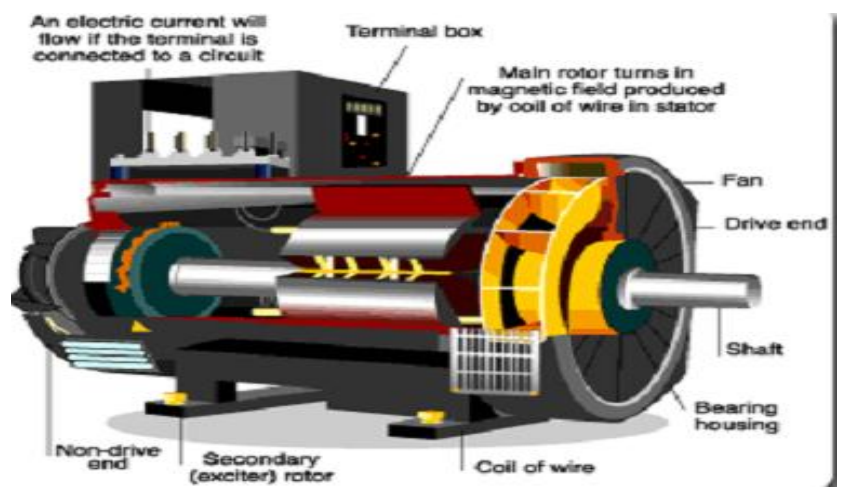

Figure 1: A synchronous generator

The static part is called stator while the rotating part is known as rotor. The rotor can be of salient and non-salient types. Their choice of use depends upon the speed desirable. For high speed non salient or round rotor synchronous generators are used while for low speed requirement salient poles synchronous generators are used. [3] In SG the field winding is on the rotor so the term rotor windings and field windings is used for each other. It is called field winding because the magnetic field is produced by these rotor windings in main synchronous generator. Similarly the voltage is collected from the stator of synchronous generator so the term armature windings and stator windings can be used interchangeably as shown in fig 2. [3]

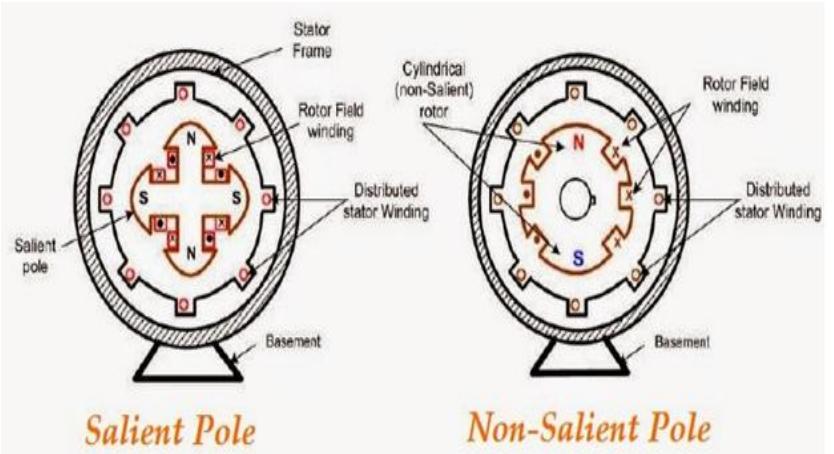

Figure 2: Salient versus non-salient poles of a SG

For the purpose of supplying DC current to the rotor of synchronous generator slip rings are used which are graphites of carbon riding on the rotor of synchronous generator as shown in fig 3. DC current can also be supplied by mounting a DC power supply directly on the top of rotor of synchronous generator. [3]

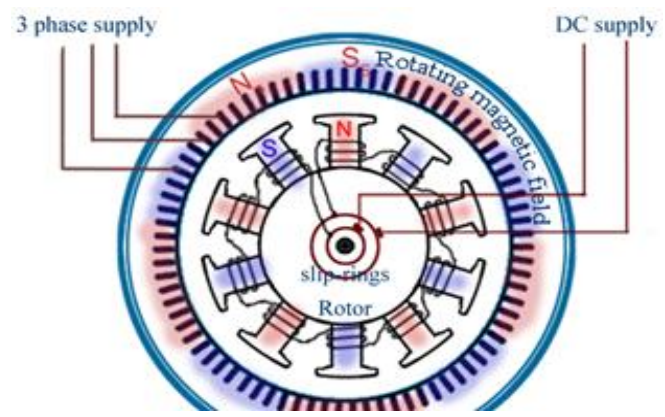

Figure 3: Dc supply with the help of slip rings

Similarly the speed of magnetic field produced can be related to the electrical frequency produced in synchronous generator by the following equation. [3]

$$
f_{e}=\frac{n_{m} P}{120}
$$




\section{International Journal of Science and Research (IJSR) \\ ISSN (Online): 2319-7064 \\ Index Copernicus Value (2013): 6.14 | Impact Factor (2014): 5.611}

Where $f_{e}$ is the electrical frequency in hertz of the voltage produced, $\mathrm{n}_{\mathrm{m}}$ is the mechanical speed of magnetic field in revolutions/min while $\mathrm{P}$ represents the number of poles in the machine. [3]

These synchronous generators provide power and show normal behaviour during steady state condition. When sudden load changes occur or severe faults occur then transients are produced. One of the severe transient condition occurs when short circuit test of synchronous generator is performed. This test is performed to calculate various time constants \& reactances of SG. These parameters determined the sharpness of the shapes of the graphs of each phase current during short circuit test. A lot of softwares such as ATP, PSCAD \& Simsen are available to check the system behaviour during transients. Matlab simulink is used to verify and validate the values of these time constants $\&$ reactances obtained after the test. [1]

First the theoretical response of short circuit test and short circuit current components of SG are described then the matlab response during the test of real time SG will be described and a comparison will be made. [3]

\section{Theoretical Response During Short Circuit}

When the three phases of stator of SG are shorted with the help of ammeters set for small SGs and through current transformers CTs and bus bars for big SGs then its response is shown as in fig 4 . [3]
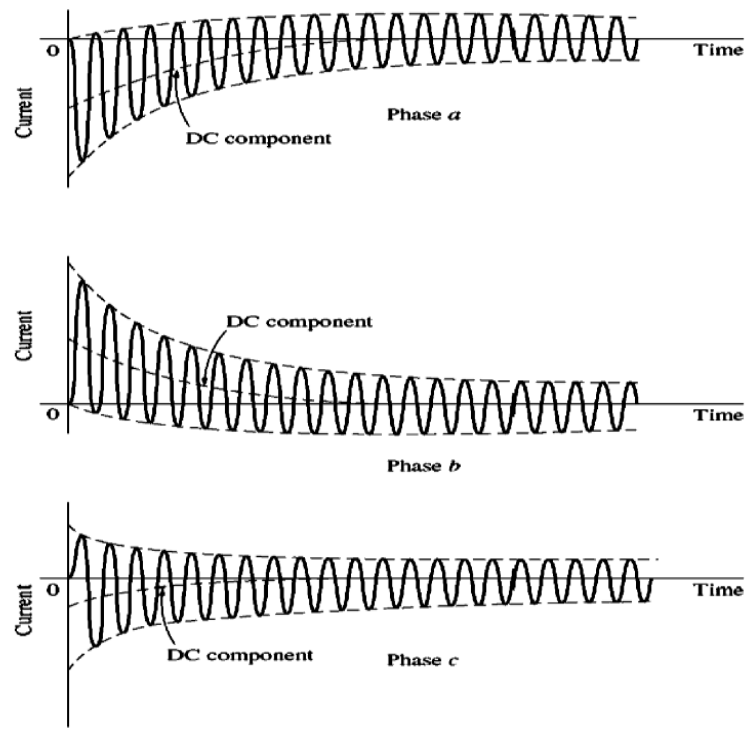

Figure 4: Three phase current flow during three phase fault

Each phase current composes of subtransient, transient \& steady state time periods. In the start the current waveform starts to decrease at a high rate and the value of current is very high. This time period is known as subtransient period. After it the current starts to minimize at a lower rate and finally achieve a stable upper \& lower fixed values, this period is known as transient period. The point after which the current oscillates between two fixed upper and lower limits and its value remains constant, that time period is called steady state period as shown in fig 5. The advantage of dividing the current into these three time periods is that separate reactances and time constants can be considered for each time period. [3]

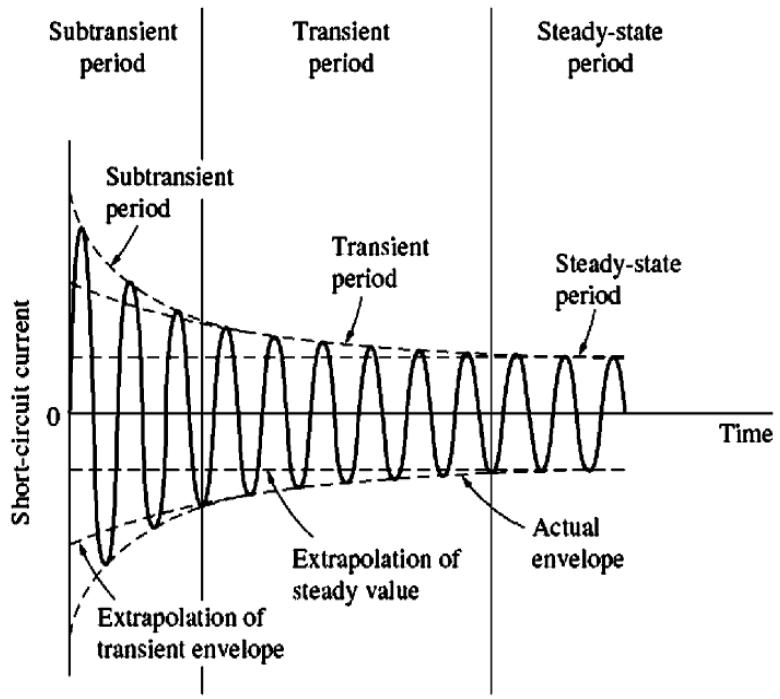

Figure 5: Subtransient, transient \& steady state periods

The current is composed up of subtransient, transient, steady state, DC value and double frequency components. Let us describe them one by one. Consider $\mathbf{T}_{\mathbf{a}}$ as the armature time constant, $\mathbf{T}_{\mathbf{d}}$ " as the subtransient direct axis time constant, $\mathbf{T}_{\mathbf{d}}$ as the transient direct axis time constant and $\mathbf{E}_{\mathbf{0}}$ as the generator voltage before short circuit. Similarly $\mathbf{X}_{\mathbf{d}}$ " and $\mathbf{X}_{\mathbf{d}}$ as subtransient and transient direct axis synchronous reactances while $\mathbf{X}_{\mathbf{q}}$ " as the quadrature axis subtransient synchronous reactance. [5]

\subsection{Sub Transient Component Of Current}

This component of current is due to damper windings of SG. It stands out for $20-60 \mathrm{~ms}$. Its instantaneous value is shown in fig 6 and can be expressed as [7].

$$
i_{k a}(\mathrm{t})=\sqrt{2} E_{0} \cdot\left[\left(\frac{1}{X_{d}^{\prime \prime}}-\frac{1}{X_{d}^{\prime}}\right) \varepsilon^{-1 / r_{d}}\right] \sin \left(\omega \mathrm{t}+\theta_{0}\right)
$$

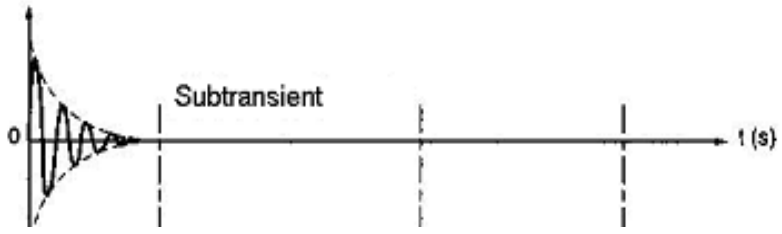

Figure 6: Subtransient current

\subsection{Transient Component of Current}

This component of current sustains for 2-5 seconds. It vanishes out as an exponential decay and reaches a steady state value. This part of the whole current is shown in fig 7 and can be mathematically described as [7].

$$
i_{k a}(t)=\sqrt{2} E_{0} \cdot\left[\left(\frac{1}{X_{d}^{\prime}}-\frac{1}{X_{d}}\right) \cdot \varepsilon^{-t / r_{d}}\right] \cdot \sin \left(\omega \mathrm{t}+\theta_{0}\right)
$$




\section{International Journal of Science and Research (IJSR) \\ ISSN (Online): 2319-7064}

Index Copernicus Value (2013): 6.14 | Impact Factor (2014): 5.611

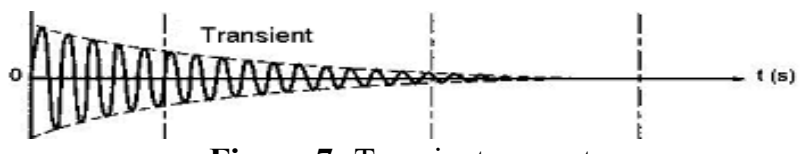

Figure 7: Transient current

\subsection{Steady State Current Component}

This part of current during a short circuit test is shown in fig 8 and is given as

$$
i_{k a \theta}(\mathrm{t})=\sqrt{2} E_{0} \cdot \frac{1}{X_{d}} \cdot \sin \left(\omega \mathrm{t}+\theta_{0}\right)
$$

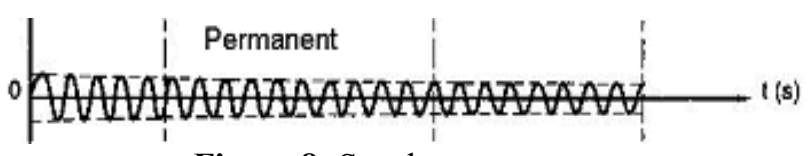

Figure 8: Steady state current

\subsection{Dc Component}

This part of current is mainly due to rotor saliency. This asymmetrical component of current depends upon the voltage $\mathbf{E}_{\mathbf{0}}$ and it vanishes as an exponential function as shown in fig 9 and is given as [7].

$$
i_{L D C}(\mathrm{t})=-\frac{\sqrt{2} \cdot E_{0}}{2}\left(\frac{1}{X^{\prime \prime}}+\frac{1}{X^{\prime \prime}}\right) \cdot \varepsilon^{-1 / t_{*} \cdot \sin \left(\theta_{0}\right)}
$$

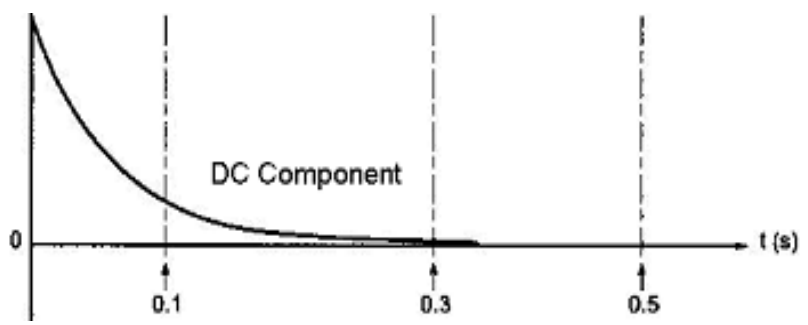

Figure 9: DC component of current

\subsection{Double Frequency Current Component}

This portion of current is assumed to be zero as Xd" and $\mathbf{X q}{ }^{\prime}$ are almost equal. [7] This is due to the magneto motive force in the field windings of the exciter and is given by

$$
i_{k_{-2} \omega}(\mathrm{t})=-\frac{\sqrt{2} \cdot E_{0}}{2} \cdot\left(\frac{1}{X_{d}^{\prime \prime}}-\frac{1}{X_{q}^{\prime \prime}}\right) \cdot \mathcal{E}^{-1 / t_{a}} \cdot \sin \left(2 \omega \mathrm{t}+\theta_{0}\right)
$$

\subsection{Phase "a" Current Components}

Thus the total current in any phase suppose phase " a" is composed of the following components of current and is given by [5].

$$
i_{k a}=i_{k a 0}+i_{k a}^{\prime}+i_{k a}^{\prime \prime}+i_{k D C}+i_{k_{-} 2 \omega}
$$

The above components of current combine and form the current in a single phase "a" of SG during short circuit test is visualized in fig $10 .[5]$

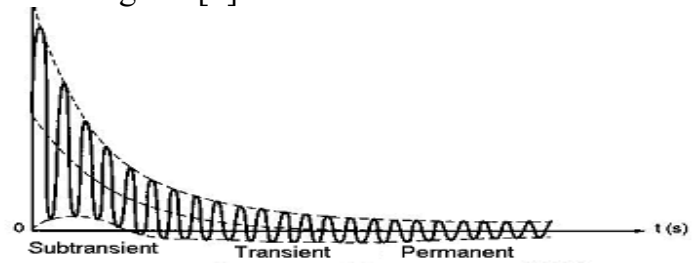

Figure 10: Current components in a single phase "a"

\section{Matlab Simulink Response During Short Circuit}

Consider 40 MVA SG unit installed at Warsak Dam Pakistan. They are manufactured by Canadian General Electric Company Limited. They are having vertical shaft overhung type with enclosing housing and have self-ventilation system, and are kept cooled by air coolers. A 200 KW direct connected exciter is connected with it. To perform the short circuit test of this SG. It is connected with series RLC load and three phase fault in the fashion as shown in fig 11. This SG is modeled with various parameters of reactances, time

\begin{tabular}{|c|c|c|c|}
\hline No. & $=$ & \multicolumn{2}{|c|}{663661} \\
\hline Model & $=$ & \multicolumn{2}{|c|}{78709} \\
\hline Type & $=$ & \multicolumn{2}{|l|}{ ATI } \\
\hline Form & $=$ & \multicolumn{2}{|l|}{ W } \\
\hline Class & $=$ & \multicolumn{2}{|c|}{$44-40000-136.3$} \\
\hline Volts & $=$ & \multicolumn{2}{|c|}{11000} \\
\hline RPM & $=$ & \multicolumn{2}{|l|}{136.3} \\
\hline Phase & $=$ & \multicolumn{2}{|l|}{3} \\
\hline Cycle & $=$ & \multicolumn{2}{|l|}{50} \\
\hline Excitation Volts & $=$ & \multicolumn{2}{|l|}{250} \\
\hline KVA & $=$ & \multicolumn{2}{|c|}{40000} \\
\hline $\mathrm{KW}$ & $=$ & \multicolumn{2}{|c|}{40000} \\
\hline Power Factor & $=$ & \multicolumn{2}{|l|}{1.0} \\
\hline Amperes & $=$ & \multicolumn{2}{|l|}{2100} \\
\hline Amp: Excitation & $=$ & \multicolumn{2}{|l|}{640.} \\
\hline Leakage reactance & $\mathrm{X}_{\mathrm{L}}$ & \multicolumn{2}{|c|}{$=0.176$} \\
\hline Stator resistance & $\mathrm{R}_{\mathrm{S}}$ & \multicolumn{2}{|c|}{$=0.00671$} \\
\hline No of poles & $\mathrm{P}$ & \multicolumn{2}{|l|}{$=44$} \\
\hline \multirow{2}{*}{\multicolumn{2}{|c|}{$\begin{array}{l}\text { Negative sequence reactance } \\
\text { Zero sequence reactance }\end{array}$}} & $\mathrm{e}=$ & 0.181 \\
\hline & & $=$ & 0.0807 \\
\hline \multicolumn{2}{|c|}{$\begin{array}{l}\text { Zero sequence reactance } \\
\text { Direct-axis open-circuit }\end{array}$} & $=$ & 3.55 \\
\hline \multicolumn{4}{|c|}{ Balanced telephone interference factor $=50$} \\
\hline
\end{tabular}
constants and other parameters such as number of poles, line to line voltage etc as given in the tables.

Table 1: General Electric Alternating Current Generator

Table 2: (Exciter)

\begin{tabular}{|lrl|}
\hline No. & $=$ & 698308 \\
Model & $=$ & 78785 \\
Type & $=$ & MPC-10 \\
KW & $=$ & 200 \\
Speed & $=$ & 136.3 \\
Volts Full Load & $=$ & 250 \\
Amps & $=$ & 800 \\
Shunt Wound $=$ & SELF-EXCITED \\
Temp.Rise =200KW & Continuous $40^{\circ} \mathrm{C}$ \\
\end{tabular}




\section{International Journal of Science and Research (IJSR) \\ ISSN (Online): 2319-7064 \\ Index Copernicus Value (2013): 6.14 | Impact Factor (2014): 5.611}

Table 3: Time constants \& Reactances calculated after a short circuit test

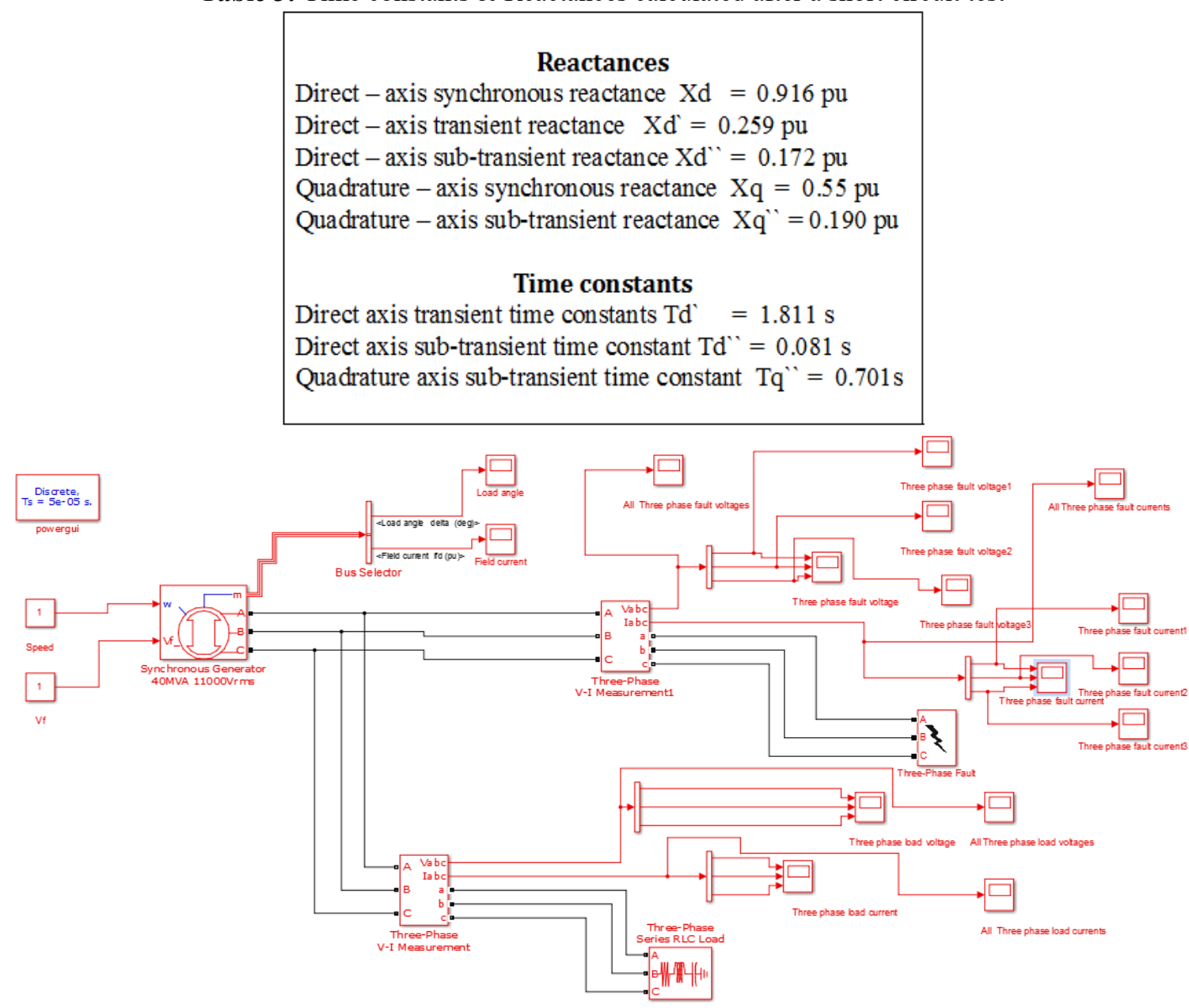

Figure 11: Matlab circuit diagram

\subsection{Matlab Simulation Results}

By simulating the circuit shown in fig 11 the following results are achieved. One scope showing the combine three phase fault currents in each phase. The different colours in the fig 12 show the three different phases of current flowing during short circuit. By comparing fig 12 with fig 5 the subtransient, transient and steady state time periods can be marked in the simulation window showing below in fig 12 .

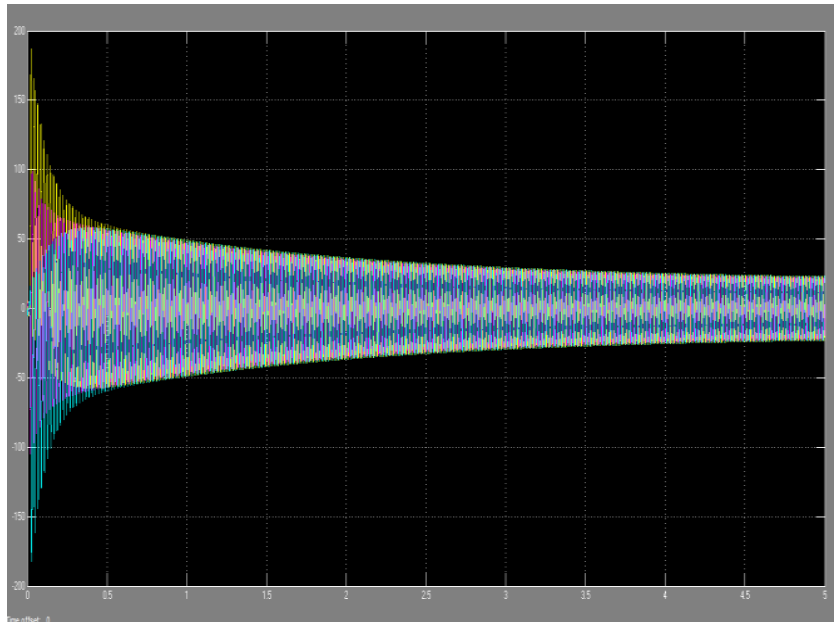

Figure 12: Subtransient, transient $\&$ steady state current components of three phases in matlab

\subsection{Matlab Simulink Three Phase Short Circuit Current}

By connecting a demux to the $\mathbf{I}_{\text {abc }}$ output current as shown in fig 11 the following transient response of each phase current of SG during short circuit can be achieved as shown in fig 13. By comparing fig 13 with fig 4 it can be verified that the matlab response during short circuit test matches with theoretical response during short circuit test of SG. 
International Journal of Science and Research (IJSR)

ISSN (Online): 2319-7064

Index Copernicus Value (2013): 6.14 | Impact Factor (2014): 5.611

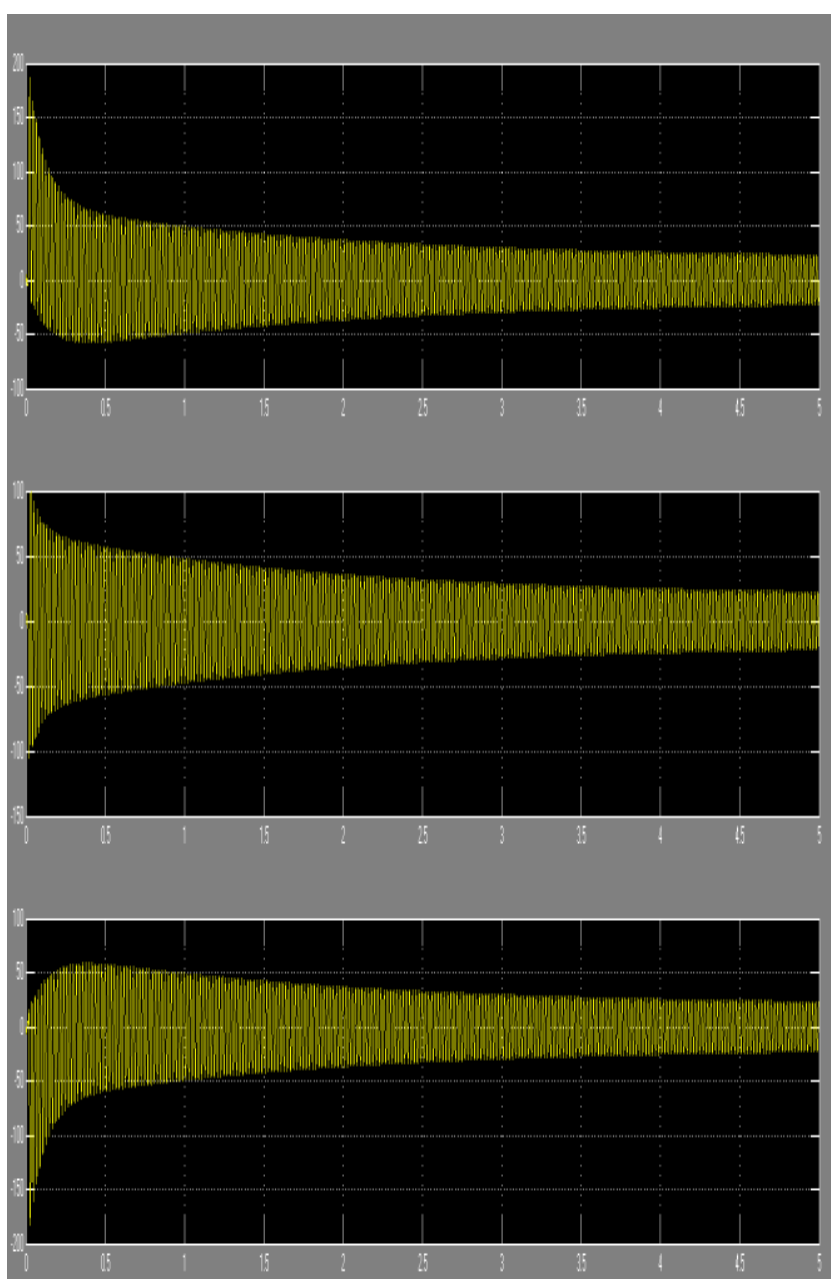

Fig 13: Three phase currents during short circuit of $40 \mathrm{MVA}$ SG in matlab simulink

\subsection{Three Phase Voltages During Short Circuit}

During short circuit of any terminal the voltage across that terminal is zero. So matlab simulink verified that argument by viewing three phase voltages $\mathbf{V}_{\text {abc }}$ of the three phase measurement as shown in fig 11 . These three phase voltages are shown as in fig 14.

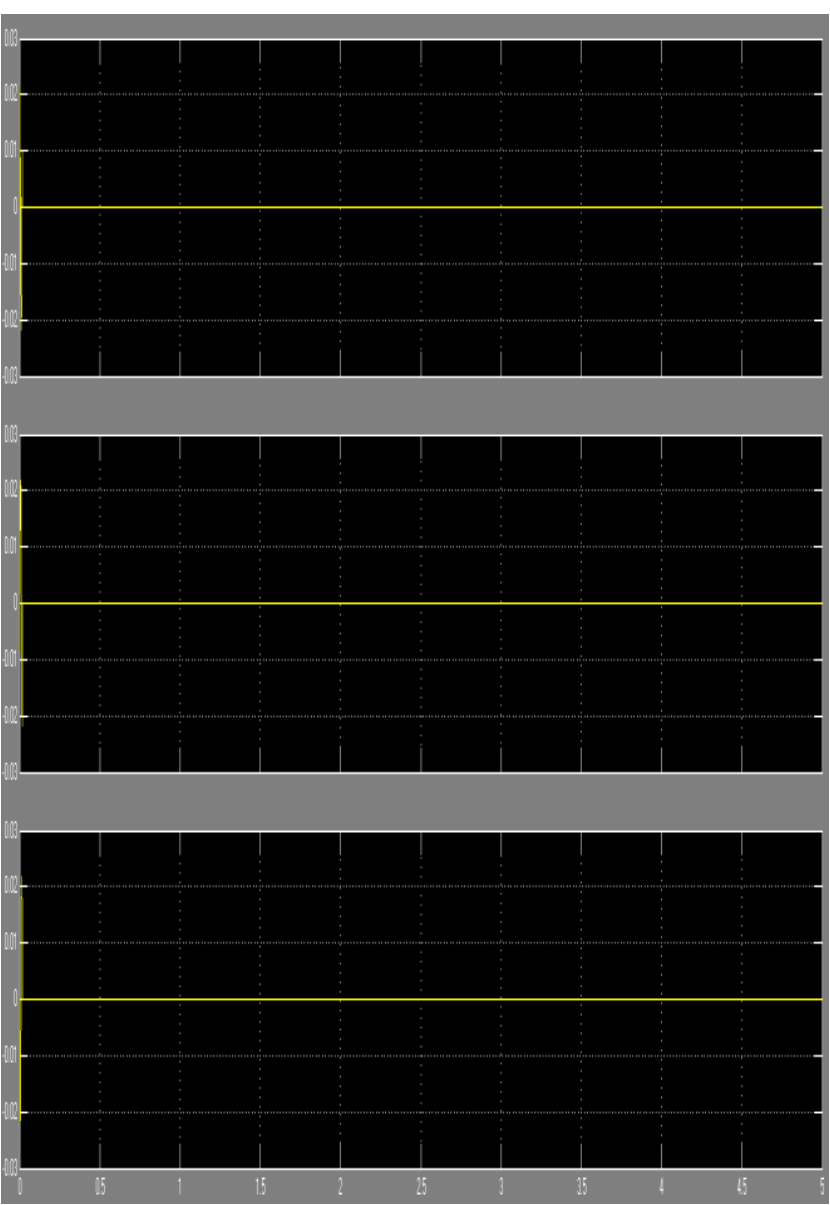

Figure 14: Three phase voltages during short circuit of 40 MVA SG in matlab simulink

\subsection{Field Current}

The field current is observed from " $m$ " point of SG and is given in fig 15 .

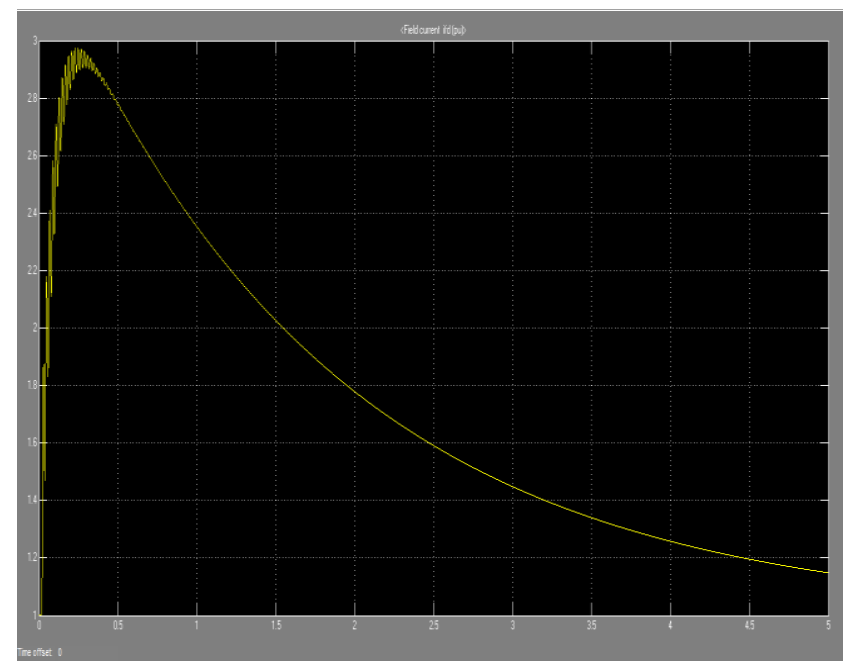

Figure 15: Field current during three phase short circuit test

\section{Conclusion and Future Recommendations}

By comparing the theoretical response and matlab rersponse, it is verified that the matlab response of SG during short circuit test matches the theoretical response of SG during the test. Hence matlab simulink is an accurate tool for checking 


\section{International Journal of Science and Research (IJSR) \\ ISSN (Online): 2319-7064}

Index Copernicus Value (2013): 6.14 | Impact Factor (2014): 5.611

the transient behaviour of synchronous machines. Another advantage of the simulink is that it gives us the opportunity that various phenomena such as load angle variation, active \& reactive power can be viewed, which cannot be observed and analyzed in a factory test. On the basis of the graphs of these quantities the system behaviour can be predicted. The response of systems in simulink can be checked for various sharp values which cannot be checked in factory test. On the basis of all results and analysis stable operating positions of synchronous machines can be deduced and conditions which are harmful for the system can be avoided.

\section{References}

[1] C. M. Apostoaia Member IEEE, "AC Machines and Drives Simulation Platform," IEEE International conference on Electric Machines \& Drives Conference (IEMDC), 15 May 2013.

[2] Samila Mat Zali, "Implementation of Synchronous Machine Parameter Derivation in Matlab," TENCON 2000. Proceedings (Volume:1 ), 24 Sep 2000.

[3] Stephen J. Chapman, "Electric machinery fundamental," ( $4^{\text {th }}$ edition), ISBN 0--07-246523-9. 2005.

[4] Aishwarya Apte, "Simulation of a Permanent Magnet Synchronous Motor using Matlab-Simulink," Annual IEEE India Conference (INDICON), 11-13 Dec 2014.

[5] F. R. Blánquez, P. Revuelta, E. Rebollo and C. A. PlateroMember IEEE, "Validation Study of the Use of Matlab/Simulink Synchronous-Machine Block for Accurate PowerPlant Stability Studies," 14th International Conference on Environment and Electrical Engineering (EEEIC), 10-12 May 2014.

[6] Juan C. Peqquena Suni, "A guide for Synchronous Generator Parameters Determination Using Dynamic Simulations Based on IEEE Standards," XIX International Conference on Electrical Machines, 2010.

[7] Laura L. Juárez-Caltzontzin, Gustavo TrinidadHernández, Tomás I. Asiaín-Olivares and Daniel RuizVega, "Theoretical and Experimental Analysis of the Short Circuit Current Components in Salient Pole Synchronous Generators," 11th Spanish Portuguese Conference on Electrical Engineering (11CHLIE), 2009, vol. 1

[8] Keith W. Klontz Senior Member IEEE, "Short-Circuit Analysis of Permanent-Magnet Generators," IEEE Transaction On Industry Application (Vol. 47, No. 4), July/August 2011.

\section{Author Profile}

Abdul Jabbar Khan received the B.Sc Electrical Engineering from University of Engineering and Technology (UET) Peshawar, Pakistan in 2010. He is now doing M.Sc Electrical (Power) Engineering from University of Engineering and Technology Peshawar, Pakistan.

Amjadullah Khattak received the B.Sc Electrical Engineering from University of Engineering and Technology (UET) Peshawar, Pakistan in 1992. He has done MS in Communications \& Electronics in 1999 from UET Peshawar. He has also completed a degree of M.sc Computer \& Communications Security from George Washington University USA in 2002. He completed his Phd from UET Peshawar, Pakistan in 2010. He is also a member in in Board of Directors for PESCO (Peshawar Electric Supply Company). Along with this he has an additional charge of Project Director for the Establishment of Wide Spread Internet Setup in the settelite \& Main Campus and hostels of UET Peshawar. 